\title{
Prevalence of needle stick injuries among nurses in a tertiary care hospital and their immediate response
}

\begin{abstract}
Jalina Laishram, Avinash Keisam, Ebenezer Phesao, M. Shyami Tarao', Valerie J. Laloo, H. Sanayaima Devi
\end{abstract}

Departments of Community Medicine, Regional Institute of Medical Sciences, ${ }^{1}$ Jawaharlal

Nehru Institute of Medical Sciences, Imphal, Manipur, India

Address for the Correspondence:

Dr. H. Sanayaima Devi, Department of Community Medicine, Regional Institute of Medical Sciences, Imphal - 795 004, Manipur, India. E-mail: drsanahj@gmail.com

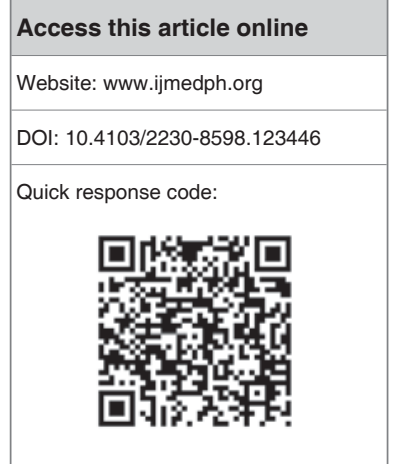

Context: Needle stick injuries (NSIs) are wounds caused by needles in health care setup that accidentally puncture the skin and may result in exposure to blood or other body fluids. NSI is a major occupational health and safety issue faced by health care professionals globally. Nurses have the highest rate of needle stick injury among health care workers. Aims: To determine the prevalence of needle stick injuries (NSIs) among the nurses, to determine the association between NSI and selected variables like age, marital status, years in service, educational qualification and to assess the measures undertaken by the respondents after the NSI. Materials and Methods: A cross sectional study was conducted in a tertiary care hospital in Imphal among nurses from October to November 2011. Self-administered questionnaire was used for data collection. Descriptive statistics were used. Chi square test was used to see the association and a $P$-value of $<0.05$ was taken as significant. Results: The prevalence of $\mathrm{NSI}$ within the last one year was found to be $28.1 \%(N=86)$. Of them $49(46.5 \%)$ had two or more NSIs in the last one year. More than half of the NSIs occurred during intravenous (IV) injection, $16.3 \%$ during intramuscular (IM) injection and only $1.6 \%$ during recapping of the needle. Eighty three $(96 \%)$ of them did not were gloves during NSI. Forty $(46.5 \%)$ of them washed the injured part with water and soap as immediate measure. Thirty seven (43\%) did not report it. Though $251(82 \%)$ knew about the free availability of Post Exposure Prophylaxis (PEP) in the hospital, only 5(5.7\%) took PEP. Conclusion: Needle stick injury is an important occupational health hazard among the nurses. Reporting to the concerned authorities, screening after NSI and promotion of safety measures should be greatly encouraged.

Key words: Cross-sectional study, needle stick injuries, nurses, post-exposure prophylaxis, prevalence

\section{INTRODUCTION}

Needle stick injuries (NSIs) are wounds caused by needles used in health-care set-up that may accidentally puncture the skin resulting in exposure to blood or other body fluids. NSI is a major occupational health and safety issue faced by health-care professionals globally. These events are of concern because of the risk of blood-borne diseases such as hepatitis B virus (HBV), hepatitis C virus (HCV) and the human immunodeficiency virus (HIV). Despite their seriousness as a medical event, NSIs have been neglected, most go unreported and ICD-10 coding is not available. ${ }^{[1]}$

World Health Organization, in its World Health Report 2002, reports that of 35 million health-care workers, 2 million experience percutaneous exposure to infectious diseases each year. Around 37.6\% of hepatitis B, 39\% of hepatitis C and $4.4 \%$ of HIV/acquired immunodeficiency syndrome in healthcare workers around the world are due to NSIs. ${ }^{[2]}$

NSIs are a common event in the health-care environment and these injuries may occur not only with freshly contaminated sharps, but also with needles that carry dry blood. Factors that increase risks of transmission of HIV include a deep wound, visible blood on the device, a hollow-bore blood-filled needle, use of a device to access an artery or vein and high-viral-load status of the patient. ${ }^{[3,4]}$ While the infectivity of HIV and HCV decrease within a couple of hours, HBV remains stable during desiccation and infectious for more than a week. The risk of transmission through NSIs for $\mathrm{HBV}$ is $1-40 \%, \mathrm{HCV}$ is $1.8 \%$ and $\mathrm{HIV}$ is $0.3 \%{ }^{\left[{ }^{[5]}\right.}$ 
Nurses have the highest rate of NSI among health-care workers. ${ }^{[6]}$ In India, authentic data on NSI are scarce. Around 3-6 billion injections are given per year, of which $2 / 3^{\text {rd }}$ injections are unsafe. ${ }^{[7]}$ The hazard of injury is further compounded by the high prevalence of HIV, $\mathrm{HBV}$, and HCV among hospitalized patients. Therefore, this study was conducted with the objectives (a) to determine the prevalence of NSIs among the nurses, (b) to determine the association between NSI and selected variables such as age, marital status, years in service, educational qualification and (c) to assess the measures undertaken by the respondents after the NSIs.

\section{MATERIALS AND METHODS}

A cross-sectional study was conducted in a tertiary care hospital of Imphal, Manipur, among all nurses from October to November 2011. All nurses working in the hospital were eligible to participate in the study. Those who refused to participate and those who could not be contacted for three consecutive visits were excluded from the study. Data were collected using a pre-tested and predesigned selfadministered questionnaire that consisted questions on particulars of the respondent and questions about the needle stick event in the last 1 year. The operational definition of NSI for the study was, "any prick to the respondent by a needle previously used on a patient, is work related and sustained within the hospital premise." For those who had more than one NSI in the last 1 year, information for the most recent NSI was taken. The respondents were approached in their respective departments and after taking an informed verbal consent, the questionnaires were distributed. The completely filled questionnaires were collected on the same day or the next day. Ethical approval was sought from Institutional Ethics Subcommittee, Regional Institute of Medical Sciences, Imphal and confidentiality was maintained. Descriptive statistics such as mean, percentage and standard deviation were used. Chi-square test was used to see the association between NSI and some selected variables of interest and a $P<0.05$ was taken as significant.

\section{RESULTS}

Out of 350 eligible respondents, 306 participated in the study with a response rate of $87 \%$. The mean age of the respondents was 40.07 $( \pm 7.91)$ years, ranging from 27 years to 62 years. The prevalence of NSI among the nurses within the last 1 year was $28.1 \%(N=86)$. Among those who reported that they had sustained NSI, 53.5\% $(N=46)$ had one, $30.2 \%(N=26)$ had two and $16.3 \%(N=14)$ had three or more NSIs.

Table 1 shows that the frequency of NSI was the highest among the age group of 41-50 years, but it was not found to be significant. Years in service were significantly associated with having an NSI and it was the highest among those who were in service between 1 year and 5 years.

Details of the most recent needle stick injury are shown in Table 2. Most NSI took place while giving intravenous (IV) injection (53.5\%), giving intramuscular (IM) injections (16.3\%) and blood withdrawal (15.1\%). Nearly $93 \%$ reported injury by an open bore needle and
$96.5 \%$ of the respondents did not wear gloves during the NSI. Majority of them (44.1\%) attributed NSI to rush hour.

Nearly, $43 \%$ did not report the NSI and only 5.7\% (5/86) took postexposure prophylaxis (PEP), though $82 \%$ of the respondents had the knowledge on free availability of PEP in the hospital.

Only $22.1 \%$ of the nurses washed the injured part with water and soap and also applied antiseptic as immediate measures after NSI.

\begin{tabular}{|c|c|c|c|}
\hline \multirow[t]{2}{*}{ Variables } & \multicolumn{2}{|c|}{ NSIs } & \multirow[t]{2}{*}{$P$ value } \\
\hline & Present, $n(\%)$ & Absent, $n(\%)$ & \\
\hline \multicolumn{4}{|l|}{ Age group (years) } \\
\hline$\leq 30$ & $4(16)$ & $21(84)$ & $d f=3 ; 0.074$ \\
\hline $31-40$ & $44(27)$ & $119(73)$ & \\
\hline $41-50$ & $26(41.3)$ & $37(58.7)$ & \\
\hline$\geq 51$ & $12(28.6)$ & $30(71.4)$ & \\
\hline \multicolumn{4}{|l|}{ Marital status } \\
\hline Unmarried & $3(50)$ & $3(50)$ & 0.355 \\
\hline Married & $83(27.6)$ & $217(72.4)$ & \\
\hline \multicolumn{4}{|l|}{ Years in service } \\
\hline$<1$ & $11(32.3)$ & $23(67.7)$ & $d f=3 ; 0.000$ \\
\hline $1-5$ & $50(54.9)$ & $41(45.1)$ & \\
\hline $6-10$ & $20(13.2)$ & $131(86.8)$ & \\
\hline $11-15^{*}$ & $4(20)$ & $20(80)$ & \\
\hline$>15^{*}$ & $1(20)$ & $5(80)$ & \\
\hline \multicolumn{4}{|c|}{ Educational qualification } \\
\hline GNM & $74(29.2)$ & $179(70.8)$ & 0.33 \\
\hline $\begin{array}{l}\text { B.Sc., and } \\
\text { M.Sc., nursing }\end{array}$ & $12(22.6)$ & $41(77.4)$ & \\
\hline
\end{tabular}

NSIs = Needle stick injuries, GNM = General nursing and midwifery, *Clubbed together for analysis

\begin{tabular}{lc}
$\begin{array}{l}\text { Table 2: Characteristics of the most recent NSI } \\
(\mathrm{N}=86)\end{array}$ \\
\hline Characteristics & Frequency (\%) \\
\hline Activities leading to NSI & \\
Giving IV injection & $46(53.5)$ \\
Giving IM injection & $14(16.3)$ \\
Blood withdrawal & $13(15.1)$ \\
Suturing/stitching & $6(7.0)$ \\
Recapping & $5(5.7)$ \\
Others & $2(2.4)$ \\
Type of needle & \\
Open bored & $80(93)$ \\
Close bored & $6(7)$ \\
Wearing gloves & \\
Yes & $3(3.5)$ \\
No & $83(96.5)$ \\
Circumstances & \\
During rush & $38(44.1)$ \\
Un co-operative patient & $22(25.6)$ \\
Lack of assistance & $20(23.3)$ \\
Fatigue & $6(7.0)$ \\
\hline NSI Needlestickiniry, M=Intramuscular IV Intravenous
\end{tabular}

$\mathrm{NSI}=$ Needle stick injury, IM = Intramuscular, IV = Intravenous 
Of all the nurses who had NSI, 72.1\% tested their blood for HIV, $29.7 \%$ for hepatitis B and $19.8 \%$ for hepatitis C. After the NSI, $24.4 \%$ received both hepatitis B vaccine and tetanus toxoid [Table 3]. About $69.9 \%$ of the nurses have ever attended any educational session, seminar or workshop related to needle stick injury [Table 4].

\section{DISCUSSION}

NSIs pose a significant occupational risk for health-care providers and it is indeed the most important occupational injuries for nurses. ${ }^{[8]}$ In our study, we found that $28 \%$ of the nurse had at least one needle stick injury during the last 1 year. Different prevalence rates (30-71.1\%) were reported from many studies conducted among different study populations. ${ }^{[9-13]}$ Our study revealed that $93 \%$ of NSI occurred by open bore needles. A lower percentages $(60-76 \%)$ were reported by other workers. ${ }^{[9,14]}$ Giving IV and IM injections and drawing blood for laboratory test were the main activities when nurses got NSI in the present study. In other studies, ${ }^{[15-17]}$ maximum number of NSIs occurred during the recapping and drawing of blood for investigations. In our study, recapping was not practiced by the majority of the respondents; this might be because $69.9 \%$ of the nurses had attended the workshop or seminars related to it. Similar findings were reported by other workers. $^{[12,15]}$ Of the injured nurses, $83(96.5 \%)$ were not using gloves, which is consistent with other reports. ${ }^{[10]}$ However, in another study only $28 \%$ of the nursing care workers in Iran did not use any personal protective equipment. ${ }^{[2]}$ In the present study, respondents indicated that work overload was the leading cause of their injury, which is consistent with other findings. ${ }^{[18]}$ In other studies, it has been shown that lack of experience in many procedures, insufficient training and fatigue leads to occupational sharp injuries. ${ }^{[19]}$

Furthermore, in this study, out of all the nurses who got NSI, majority of them $(94.3 \%)$ did not take PEP. Similar findings were reported by other researchers. ${ }^{[9,13]}$ A more recent survey of all types of providers from Iowa Medical Organization found that 34\% reported their exposure to an employee health service. ${ }^{[20]}$ The risk of under reporting and thus delaying or foregoing treatment is significant. HIV, hepatitis B, and hepatitis C being highly prevalent in the state of Manipur, the chances of being infected by these diseases are high as our study indicates that most needle pricks went unreported and untreated by PEP. Reporting the injury to an authorized center enables counseling regarding the risk of exposure and prevention to secondary transmission, including possible transmission to patients.

We conducted the study among the nurses because they are at higher risk for needle stick injury. The results might not be generalized to all nurses working in other hospitals in the state. Reporting to the concerned authorities, screening after NSI and promotion of safety measures should be greatly encouraged.

NSIs among nurses are common and are often not reported and the majority of them did not take PEP. These findings warranted the need for ongoing attention to strategies to reduce such injuries in a systematic way and to improve reporting system so that appropriate medical care can be delivered.

\begin{tabular}{lc} 
Table 3: Measures undertaken by the respondents \\
after NSI (N=86) & Frequency (\%) \\
\hline Measures undertaken & $6(7.0)$ \\
\hline Immediate measures & $40(46.5)$ \\
Wash with water only & $4(4.7)$ \\
Wash with water and soap & $12(14.0)$ \\
Applied antiseptic only & \\
Wash with water and applied & $19(22.1)$ \\
antiseptic & $5(5.7)$ \\
Wash with water and soap and & \\
applied antiseptic & \\
Wash with water and soap and & \\
applied antiseptic and PEP & \\
Blood test done after NSI* & \\
multiple answers & $62(72.1)$ \\
Done HIV testing & $25(29.1)$ \\
Done HBV testing & $17(19.8)$ \\
Done HCV testing & $13(15.2)$ \\
Vaccination taken after NSI & $47(54.6)$ \\
Hepatitis B vaccine & $21(24.4)$ \\
Tetanus toxoid & $5(5.8)$ \\
Both hepatitis B vaccine and & \\
tetanus toxoid & None
\end{tabular}

$\mathrm{NSI}=$ Needle stick injury, HIV = Human immunodeficiency virus, $\mathrm{HBV}=$ Hepatitis B virus, $\mathrm{HCV}=$ Hepatitis $\mathrm{C}$ virus, PEP $=$ Post-exposure prophylaxis

Table 4: Ever attended any educational session,
seminar or workshop
\begin{tabular}{lc} 
Attended & $\boldsymbol{n}(\%)$ \\
\hline Yes & $214(69.9)$ \\
No & $92(30.1)$ \\
\hline
\end{tabular}

\section{ACKNOWLEDGMENTS}

We thank the Medical Superintendent for allowing us to conduct the study, the fourth semester MBBS students who were posted in community medicine for helping us in data collection.

\section{REFERENCES}

1. Needle stick injury. Available from: http://www.en.wikipedia.org/wiki/ Needlestick_injury. [Accessed on 2011 Sep 27].

2. Occupational health. Available from: http://www.who.int/occupational_ health/topics/needinjuries/en/index.html. [Accessed on 2011 Sep 27].

3. Cardo DM, Culver DH, Ciesielski CA, Srivastava PU, Marcus R, Abiteboul D, et al. A case-control study of HIV seroconversion in health care workers after percutaneous exposure. Centers for disease control and prevention needlestick surveillance group. N Engl J Med 1997;337:1485-90.

4. Ippolito G, Puro V, Heptonstall J, Jagger J, De Carli G, Petrosillo N. Occupational human immunodeficiency virus infection in health care workers: Worldwide cases through September 1997. Clin Infect Dis 1999;28:365-83.

5. Sarrazin U, Brodt HR, Sarrazin C, Zeuzem S. Prophylaxis against HBV, HCV and HIV after occupational exposure. Dtsch Arztebl 2005;102:2234-39.

6. ICN on preventing needle stick injuries. Nursing matters: Fact sheets 2009. Available from: http://www.medicalkenya.co.ke/2011/02nursingmatters who_fac_sheet. [Accessed on 2011 Sep 29]. 
7. Muralidhar S, Singh PK, Jain RK, Malhotra M, Bala M. Needle stick injuries among health care workers in a tertiary care hospital of India. Indian J Med Res 2010;131:405-10.

8. Ebrahimi H, Khosravi A. Needle stick injuries among nurses. J Res Health Sci 2007;7:56-62.

9. Ghofranipour F, Asadpour M, Ardebili HE, Niknami S, Hajizadeh E. Needle sticks/sharps injuries and determinants in nursing care workers. Eur J Sport Sci 2009;1:191-7.

10. Meunier O, Almeida N, Hernandez C, Bientz M. Blood exposure accidents among medical students. Med Mal Infect 2004;31:537-43.

11. Patterson JM, Novak CB, Mackinnon SE, Ellis RA. Needle stick injuries among medical students. Am J Infect Control 2003;31:226-30.

12. Askarian M, Malekmakan L. The prevalence of needle stick injuries in medical, dental, nursing and midwifery students at the university teaching hospitals of Shiraz, Iran. Indian J Med Sci 2006;60:227-32.

13. Shiao JS, Mclaws ML, Huang KY, Guo YL. Student nurses in Taiwan at high risk for needle stick injuries. Ann Epidemiol 2002;12:197-201.

14. Nsubuga FM, Jaakkola MS. Needle stick injuries among nurses in subSaharan Africa. Trop Med Int Health 2005;10:773-81.

15. Manzoor I, Daud S, Hashmi NR, Sardar H, Babar MS, Rahman A, et al. Needle stick injuries in nurses at a tertiary health care facility. J Ayub Med Coll Abbottabad 2010;22:174-8.

16. Zafar A, Aslam N, Nasir N, Meraj R, Mehraj V. Knowledge, attitudes and practices of health care workers regarding needle stick injuries at a tertiary care hospital in Pakistan. J Pak Med Assoc 2008;58:57-60.

17. Azap A, Ergönül O, Memikoğlu KO, Yeşilkaya A, Altunsoy A, Bozkurt GY, et al. Occupational exposure to blood and body fluids among health care workers in Ankara, Turkey. Am J Infect Control 2005;33:48-52.

18. Makary MA, Al-Attar A, Holzmueller CG, Sexton JB, Syin D, Gilson MM, et al. Needle stick injuries among surgeons in training. N Engl J Med 2007;356:2693-9.

19. Rogers B, Goodno L. Evaluation of interventions to prevent needle stick injuries in health care occupations. Am J Prev Med 2000;18:90-8.

20. Doebbeling BN, Vaughn TE, McCoy KD, Beekmann SE, Woolson RF, Ferguson KJ, et al. Percutaneous injury, blood exposure, and adherence to standard precautions: Are hospital-based health care providers still at risk? Clin Infect Dis 2003;37:1006-13.

How to cite this article: Laishram J, Keisam A, Phesao E, Tarao MS, Laloo VJ, Devi HS. Prevalence of needle stick injuries among nurses in a tertiary care hospital and their immediate response. Int J Med Public Health 2013;3:257-60.

Source of Support: Nil, Conflict of Interest: None declared. 